\title{
A Design Science Approach to Virtual World Implementation of Trade Fairs
}

\author{
Ramesh Sharda \\ Institute for Research in Information Systems \\ Spears School of Business \\ Oklahoma State University \\ Ramesh.sharda@okstate.edu \\ David Sikolia \\ Spears School of Business \\ Oklahoma State University \\ David.Sikolia@okstate.edu \\ Joseph Thomas \\ Management Department \\ The United States Air Force Academy \\ Joseph.Thomas@Usafa.edu
Ramesh Sambasivan
iTradeFair.com, Inc.
Wyomissing, PA
ramesh@itradefair.com

\begin{abstract}
Virtual world technology platforms, which allow users from distant places to congregate virtually for entertainment or other purposes, are growing into useful tools for businesses and consumers. Besides other applications, the concept of same-time, different-place gatherings can also be used to organize virtual trade fairs that are complements or extensions of physical tradeshows. This paper describes a design-science approach to the development of a virtual world technology platform specifically aimed at creating virtual tradeshow events that bring show attendees and exhibitors together. After describing the design and development of the virtual world technology platform and some of its applications, we report its implementation in a career fair setting organized to facilitate interaction between would-be employers and students at a university.. We also conducted a preliminary evaluation of the effectiveness and efficiency of this virtual event by surveying employers and attendees. Although the event effectiveness is rated average, this exploratory analysis reveals that the virtual events are quite efficient in terms of use of resources. The overall effort to develop the virtual events is minimal as compared to the number of additional attendees that can participate in the event, reducing the cost per new lead generated. As the technology evolves further to enhance richness of the interactions, these virtual events will become major applications of virtual worlds.
\end{abstract}

Keywords: Virtual Worlds, Tradeshow, Design Science, Virtual Career Fair 


\section{Introduction}

This paper describes a design-science-based approach to a real application of virtual worlds that has been developed by IS academic entrepreneurs using theories grounded in information systems research. In the Merriam-Webster dictionary (Tradeshow, 2012), a tradeshow is defined as "a large exposition to promote awareness and sales especially of new products within an industry. " Tradeshows or trade fairs are an important advertising venue for many products and services. For example, technology companies, electronics developers, weapons manufacturers, personnel hiring officers and candy manufacturers all use trade fairs to find qualified leads that can be converted into customers or clients.

Traditional approaches to finding these leads include advertising in various media, sponsorships, and giveaways. Participating in tradeshows represents about $10 \%$ of the marketing communications budget for US firms and more than $20 \%$ for many European firms (Sandler, 1994). Career fairs or job fairs give employers a chance to screen a large number of job candidates while simultaneously giving potential employees the opportunity to meet and screen a large number of employers. In summary, traditional trade fairs and career fairs enable businesses to interact with new or existing clients and potential employees in the same place and at the same time in order to meet their strategic requirements. Virtual gatherings variously termed as trade fairs, tradeshows, expos, etc. enabled through this application have complemented traditional gatherings and enabled new events that may not have been economically feasible in a purely face-to-face (f2f) environment.

The tradeshow industry faces the growing problems of rising costs and accessibility in an economy and business market that are becoming more and more global. According to E\&E Exhibit Solutions, the average cost of individual portable tradeshow booths is between $\$ 100-\$ 150$ per square foot. A standard 10x10 pop-up display can cost between
$\$ 10,000$ and $\$ 15,000$ (E\&E, 2008). In addition, the rising cost of transportation and shipping mean that the tradeshow industry needs to find ways to help exhibitors achieve a decent return on their investment in tradeshow participation. The Internet has created new avenues for reaching tradeshow attendees. The drawing power of an event and the global reach of the Internet can be combined into online events or a virtual trade fair (VTF), defined as a collection of exhibitorcreated information booths on products and services for an event that replicates (and even enhances) many of the information exchange, communication, and community gathering aspects of a physical event (Kirchgeorg. et al., 2005). Such a combination can create value for both the tradeshow attendees and exhibitors.

This paper describes the implementation of a technology platform (artifact) to enable any tradeshow organizer to create a virtual event. This platform has been used commercially to host virtual events of many different types-career fairs, trade shows, procurement events, etc. The technology artifact was conceived and designed by an information systems academic researcher, and the company, iTradeFair.com, was cofounded by two of the authors of this paper. iTradeFair.com provides tradeshow organizers the VTF technology and services for implementing a virtual show. The virtual trade fair is promoted the same way as a physical trade fair, using mail or e-mail advertising to build attendee traffic and convince exhibitors to rent virtual booth space. Exhibitors create virtual trade fair booths within the specifications stipulated by the trade fair producers. Attendees log on to the VTF and participate in the trade fair directly from the comfort of their own home or office computer. They can choose the booths to visit and click on various buttons or icons to exchange business cards, download the exhibitor's promotional literature and catalogs, or request that such information be mailed to them. Attendees can also visit the exhibitors' websites, watch an exhibitor video, chat online with exhibitors, or request an instant 
phone conversation with a worker at the virtual booth using the autodial feature.

The next section introduces tradeshows, virtual worlds, and virtual tradeshows. In Section 3 we explain the process of developing a virtual tradeshow technology platform based on design science research methodology, followed by a description of a specific virtual career fair event that was organized and hosted through our VTF technology. We also conducted an exploratory analysis of the virtual career fair participants. Evaluation and results of this analysis are presented in the evaluation of artifact section. Finally, we conclude with implications of the results and suggestions for future research.

\section{Tradeshows, Virtual Worlds, and Virtual Tradeshows}

This section provides a brief overview of the tradeshow industry and the applications of virtual worlds to create virtual tradeshows.

\section{Tradeshows}

"Tradeshow" is only one of numerous terms describing a temporary market event, held at some intervals, where a large number of buyers (attendees) and sellers (exhibitors) interact for the purpose of learning about new goods and services, (Kirchgeorg. et al., 2005). Tradeshows such as book shows, technology shows, and human resource shows (career fairs) are held worldwide throughout the year. The aims can be divided broadly into selling and non-selling activities whereby lead generation and selling are part of the direct goals, and making contacts and image building are more indirect goals. Physical tradeshows allow face-to-face interactions, the richest form of communication. However, some disadvantages of traditional tradeshows include restricted geographical reach, limited opening hours, entrance charges, and the need to get maximum exposure through the strategic location of exhibition stands (Lee-Kelly et al., 2004).

Tradeshow research has focused on tradeshow objectives, decision to participate, choice of which event to attend, sales tech- niques, and evaluating effectiveness from the perspective of both exhibitors and attendees (Kare, 1996). Exploratory studies on tradeshow functions and performance (Kerin et al., 1987), the effect of tradeshows on sales and profits (Gopalakrishna et al., 1995b), and development of models that can be used in evaluation of trade-offs among the different decision variables (Gopalakrishna et al., 1995a) are examples of some research areas. When combined with the cost of travel, tradeshows represent a major industry in itself, but with only a limited amount of academic research (Kare, 1996).

\section{Virtual worlds}

Virtual worlds have existed for a long time in various forms including stereoscope, cinemarama, simulators, computer-games, and head-mounted displays. The term virtual world is a broad concept referring to a computer generated artifact (Charturvedi et.al., 2011). For the purposes of this paper, we define virtual worlds as artificial worlds created by computer systems in which the user has the impression of being immersed. The intention is to achieve a feeling of telepresence and participation (Mikko et al., 2007). In the past, virtual worlds included only technological innovations but now the focus has shifted from a technological view to a social and usage view (Mikko et al., 2007). Current virtual worlds are three-dimensional simulated worlds (Iris et al., 2007; Nah et.al., 2011) and include for example Second Life (http://www.secondlife.com), and EverQuest (www.everquest.com). In these virtual worlds trees move with the wind, water flows down a stream, birds chirp in the trees, and trucks roar in the street. Every user creates a digital character called an 'avatar' to interact, walk, talk, and even run global businesses in real time with other computer-generated individuals in the computer-generated landscapes (David et al., 2007).

Real world institutions ranging from universities and businesses to governmental organizations are increasingly involved in virtual worlds as part of their strategic marketing initiatives. Virtual worlds are becoming an im- 
portant channel for reaching a wider consumer base, as well as for "seeing" the customers and interacting with them in a way that was not possible a few years ago (Lakshmi et al., 2007). Virtual currencies often allow participants to buy or sell virtual goods such as attire and services such as training. In 2011, revenues from virtual items were expected to reach $\$ 7.1$ billion globally; furthermore, virtual worlds have over 1 billion registered users (Wasko et.al, 2011). Virtual worlds provide enhanced modes of advertising that can be immersive or absorptive, active or passive. This advertising can have a 3D format, and include audio and video in addition to text (Stuart, 2007), and therefore can enhance product knowledge and the attitude and purchase intention of customers (Tsz-Wai et al., 2007). Although studies on the use of online avatars in marketing are few, some evidence suggests that avatars and virtual representations may positively influence trust and online purchasing intention (Stuart, 2007) because they simulate experiences customers have in real stores. Studies have shown that the more an avatar resembles a user, the more likely the user will have positive attitudes towards the avatar and the products advertised using the avatar (Kil-Soo et.al., 2011). However, not all real-world attributes can be experienced virtually because not all of the human senses (i.e., taste) can be digitized and presented on a computer monitor (Tsz-Wai et al., 2007).

Although these virtual worlds are becoming interesting tools for businesses and consumers, some short-term technical and practical considerations have kept these tools from gaining widespread acceptance. First, participation in most of these virtual world environments requires downloading of specialized software. Although it is just a matter of downloading and installing (usually) free software, many businesses and government organizations prohibit any kind of software downloads on employees' computers. This restriction is even more stringent in military organizations (Evans, 2008). Also, navigation through such virtual worlds requires at least some basic training. It is thus attractive to look for appli- cation platforms that are perhaps not as media rich as the latest virtual worlds, but sufficiently rich to enable virtual experiences without requiring any downloads. One such category of virtual world applications is virtual trade show platforms, which are introduced next.

\section{Virtual Tradeshows}

A virtual tradeshow is held in cyberspace and is usually viewed as an extension of the physical exhibition (Lee-Kelly et al., 2004). It replicates many of the information exchange, communication, and community gathering aspects of a physical event. A virtual tradeshow thus has an event orientation and is capable of supporting information exchange among various exhibitors and numerous attendees. Its structure often includes a virtual exhibit hall which users enter either to attend and view virtual tradeshow displays or to build virtual booths to exhibit information, just as they would at a trade fair in a convention center.

Visitors fill out an online registration form to create a digital badge before entering the virtual exhibit hall to visit various booths. The virtual booths often look like real-world tradeshow booths with desks and displays that users can relate to easily. The virtual tradeshow may have other components such as a virtual web conference, web seminars (or webinars), or other educational presentations. Detailed tracking mechanisms enable organizers to record and analyze the flow of traffic in the virtual tradeshow. Virtual tradeshows can serve as international tradeshows, business match-makers, procurement fairs, and product launches. The experience also translates well for other applications such as virtual job fairs, virtual benefits fairs, online employee networks, distributor fairs, and venture capital fairs.

\section{Design-Science-Based Approach}

In the following sections, we adopt the design science methodology (Hevner et al., 2004; March et al., 1995; Nunamaker Jr. et al., 1990; Peffers et al., 2007) to describe a specific implementation of virtual world technolo- 
gies to enable hosting of virtual trade fairs. As recommended in the design science guidelines, we first present the analysis and design, followed in subsequent sections by descriptions of the implementation of the artifact.

\section{Analysis and Design of the Artifact}

In this section, we identify the problem and the motivation for finding a solution and present arguments for what a better artifact will accomplish. We also present and explain 12 design guidelines generated through our understanding of tradeshow business combined with Information Systems theories

\section{Problem Identification and Motivation}

Tradeshow participation represents a major segment of the advertising and marketing budget in most industries. All organizations must address the need for qualified leads (and new sales) and, according to research conducted by the Center for Exhibition Industry Research (CEIR), $88 \%$ of the exhibitors reach new leads at a tradeshow (Ducate, 2004). In addition to new leads, organizations are also motivated to attend tradeshows for non-sales reasons. According to CEIR, $81.9 \%$ do so to present a positive company image, $76.6 \%$ for networking, $68.1 \%$ to generate leads, $64.2 \%$ to introduce new products/services, $56.9 \%$ to gather competitive intelligence, $42.0 \%$ to sell products/services, and $35.1 \%$ for press coverage opportunities (Ducate, 2004).

The cost to participate in the show is also a big factor. According to a 2003 EXHIBITOR Magazine Readership Study (Armstrong, 2003), exhibit-space rental accounts for roughly one-third of a typical company's totalshow costs. If the floor space costs $\$ 21.50$ per square foot, a standard $10 \times 10$ space rental per day is $\$ 2,150$, and participating in a 3 -day event will cost approximately $\$ 6,450$. For a 20x20 space, the business will expect to pay $\$ 25,800$ to participate. Multiplying these figures by three gives an estimated cost, however, because costs for travel and shipping have gone up considerably, these numbers are low estimates (Armstrong, 2003).
In addition to the event costs, exhibitors must pay for storage of booth hardware and paraphernalia. The average annual cost for a $10 \times 10$ storage unit is between $\$ 732$ for the North Central region in the US and $\$ 1128$ for the West coast (Clemmer, 2008). Whether companies store their exhibit in one of their facilities or pay for external storage, these additional costs cannot be avoided.

Tradeshow exhibitors incur these costs in the hope of reaching their target audience. Total attendance at a tradeshow affects the value to the exhibitor of participating in the event. A common indicator of effectiveness of any marketing initiative is cost per lead (CPL). An industry expert's benchmark for CPL suggests that these costs vary from a low of $\$ 10$ $\$ 100$ per lead for email advertising to a high of $\$ 350-\$ 1500$ per lead through a tradeshow.

Although the final CPL vary greatly and there is a concern that a marketing strategy focused on CPL will lead to watered down leads of poor quality and low accuracy (Gaffney, 2008) it is clear that CPL of tradeshows far exceeds that of other methods. While tradeshows result in invaluable face-toface contact with industry peers, their periodic and geographical nature as well as escalating costs have affected physical participation. Indeed, some shows, like Comdex, that were once very popular have been cancelled due to high cost and declining participation (Markoff, 2004). From an attendee perspective, the costs to attend have also significantly increased the gap between those who are willing to attend and those who are able to attend. For example, consider academic meetings for information systems professionals. According to the Association for Information Systems (AIS), the active AIS membership in 2011 was approximately 4000 . However, the attendance at their most recent conference, the Americas Conference on Information Systems (AMCIS) in 2011 was about $713,18 \%$. It is fair to assume that many of the active members would attend their organization's major annual conference if they could. The annual International Conference on Information Systems (ICIS), a prestigious gathering of information systems academics and 
research-oriented practitioners, had an attendance in 2011 of 1382 . Even if we only consider the AIS active members, which are by no means a complete list of those interested in IS research around the world, only $35 \%$ actually attended the \#1 conference in their field. This confirms the view that there is a much larger pool of prospective attendees than those who actually attend a physical event. If the constraints of travel (budget, time, visa requirements) were absent, a higher proportion of prospective attendees would presumably participate. Although these two data points are based on academic conference attendee pool and actual attendees, our discussions with industry colleagues confirm the belief that only a fraction of those who want to attend an event actually do. This attrition is due to constraints of cost, time, travel restrictions, and so on.

\section{Objectives of a Solution}

One solution many organizations have taken to address the problems with tradeshows is field marketing. Field marketing refers to either static or touring events designed to expose people to companies, brands, or products. The advantage of touring events is that they can be geographically targeted to particular consumers. However, field marketing events target consumers more than businessto-business tradeshows.

Some information technology tools mimic the specific activities of tradeshows. The Internet has created opportunities for reaching clients through web sites, web advertising, participation in vertical portals, and so on. Communication tools can be either asynchronous or synchronous (Ashley, 2003). Asynchronous tools such as e-mail, blogs, and web pages are necessary for business but cannot begin to fill the multifaceted role of tradeshows. One possible synchronous solution is webinars, presentations, lectures, or seminars that are transmitted over the web (Good, 2005). These tools typically offer a one-way communication from presenter to audience, but can be made interactive with the ability to give, receive, and discuss information between the presenter and the audience. However, webi- nars cannot deliver the content, stakeholder information, and lead data available to an exhibitor visiting with a customer at a traditional tradeshow.

These solutions fail to address the problems faced by tradeshows: the high cost-to-lead ratio for exhibitors, and a decreased attendance due to increased travel costs; they also neglect the issue of and restricted computer access and untapped potential attendee markets. Furthermore, any solution to these problems must consider the evolving attendee base and its members' millennial interactive learning style. Finally, any solution must conform to security restrictions on downloads or plug-ins.

One solution to the challenging problem of providing the benefits of a trade fair while reducing the cost comes from virtual worlds. Virtual world technology is useful in replicating a tradeshow participation experience by organizing virtual events that can extend the reach of the event to include many more attendees and perhaps even more exhibitors.

\section{Design and Development}

The goals of enhancing tradeshow participation effectiveness and efficiency led us to design and develop a virtual trade fair platform grounded in information systems theories. Building a virtual tradeshow platform required a thorough understanding of how the physical tradeshows operate in addition to knowledge of IS theories. First, the basis of virtual tradeshows is "same-time, different-place" communication among many exhibitors and attendees (DeSanctis, 1987). Different communication media vary in "richness" based on four criteria: feedback, multiple cues, language variety, and personal focus. The richest communication medium is face-to-face meetings, followed by telephone, chat, e-mail, and memos and letters (Daft et al., 1986). Secondly, for exhibitors, attendees, and producers to transition from the physical tradeshows to virtual tradeshows, there has to be a fit between tradeshow activities or tasks and information technology substitutes. The task-technology fit (Goodhue et al., 1995) factors-quality, locatability, authorization, 
compatibility, ease of use/training, production timeliness, systems reliability, and relationship with users-guided us in producing just enough technology features to replicate the physical show experience. Third, in addition to the factors above, for the exhibitors, attendees, and producers to accept the new technology, they must perceive the system as useful (Davis, 1989). Finally, facilitation of interaction between exhibitors and attendees was guided by research in group work and collaboration (DeSanctis, 1987). Figure 1 illustrates how the tradeshow functionality and IS theories combine to guide the design of this platform.

Table 1 shows activities that take place at a physical tradeshow and notes those we could replicate in the virtual world. In addition, suggestions are made for additional or alternate activities available in a virtual tradeshow.
When show attendees visit a virtual trade-fair they see a list of show pavilions. These pavilions are product/service categories within which the exhibitor booths are organized. The attendees then visit specific exhibitor booths which have been built by the exhibitors using the technology platform and the process described in the next several pages. A sample booth is displayed in Figure 2.

As can be seen from this virtual booth image, many of the activities that take place in a f2f event can be completed in the virtual event as well. The attendees can click on different icons to visit the exhibitor's website, watch an exhibitor's video, chat online with the exhibitor's staffers, or request the virtual booth to automatically dial their telephone for an instant phone conversation. In addition, a VTF can include keynote speeches and other presentations that the show participants can attend through the virtual event page.

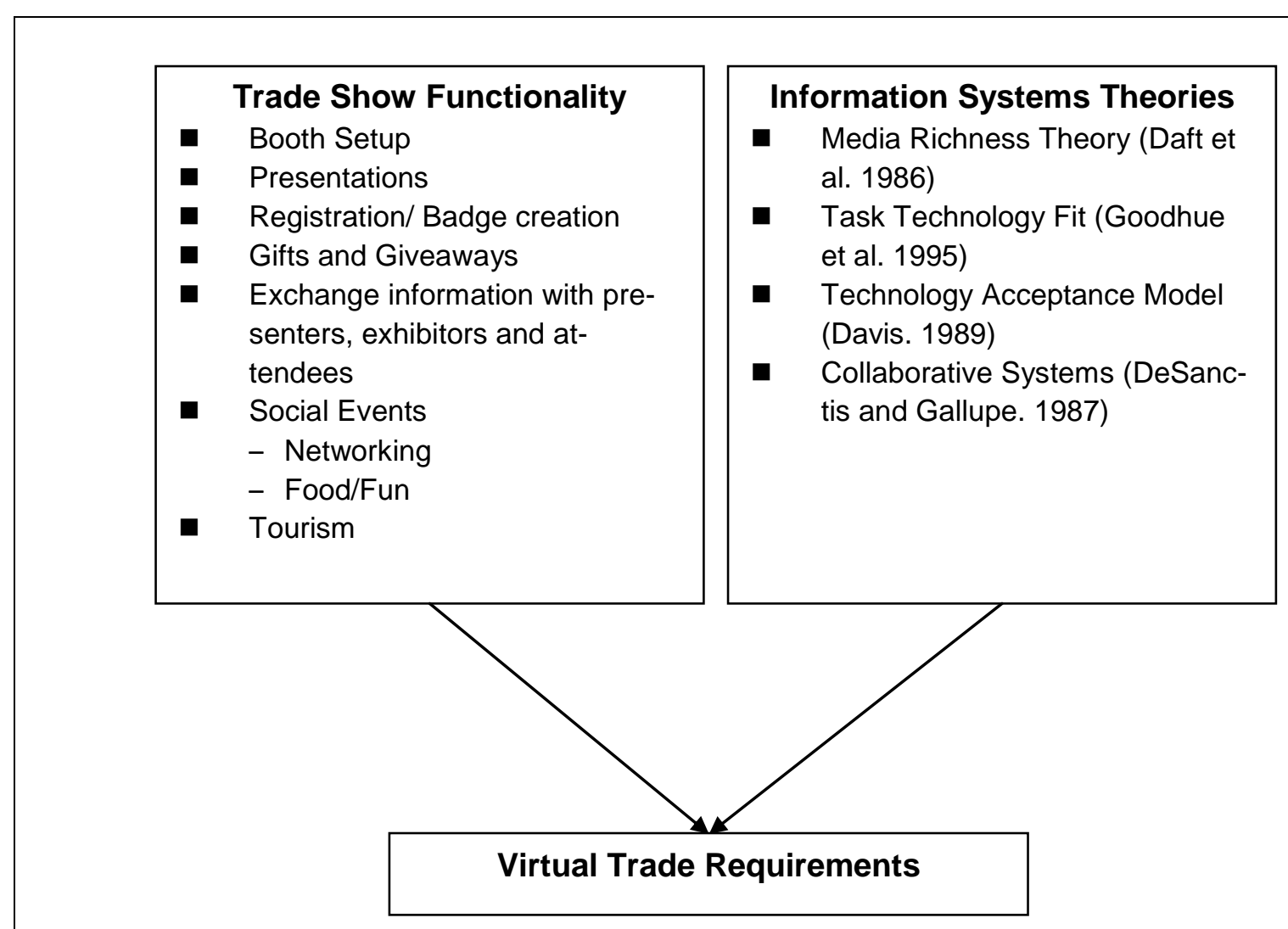

\section{Figure 1 - Platform design guided by tradeshow activities and IS research}




\begin{tabular}{|c|c|c|}
\hline Parameters & Conventional Trade Fairs & Online Trade Fair \\
\hline Logistics & $\begin{array}{l}\text { Moving people and exhibits involves travel } \\
\text { and freight costs. }\end{array}$ & Digital transmission at little or no cost. \\
\hline Booth space & Limited & No Limits \\
\hline Attendee Comforts & $\begin{array}{l}\text { Travel in planes, eat hotel food, try to } \\
\text { cover large exhibit floors }\end{array}$ & $\begin{array}{l}\text { Bookmark favorite booths and conduct visit } \\
\text { online from the comfort of the home/office }\end{array}$ \\
\hline $\begin{array}{c}\text { Get a Badge / Drop a } \\
\text { Business Card }\end{array}$ & $\begin{array}{l}\text { Each vendor rents the badge reader that } \\
\text { gathers information, or collects the busi- } \\
\text { ness cards. }\end{array}$ & $\begin{array}{l}\text { The online attendee creates a virtual } \\
\text { badge, and each virtual booth gathers the } \\
\text { information through reports of attendee's } \\
\text { booth interaction }\end{array}$ \\
\hline The Exhibit Panels & $\begin{array}{l}\text { Special companies handle this in a real } \\
\text { world trade fair }\end{array}$ & $\begin{array}{l}\text { The exhibitor completes an online form and } \\
\text { submits media files. A dynamic database } \\
\text { puts together the booth automatically. An } \\
\text { exhibitor can customize the booth }\end{array}$ \\
\hline $\begin{array}{l}\text { Gifts, Giveaways, } \\
\text { and Product Samples }\end{array}$ & $\begin{array}{l}\text { Exhibitor ships and carries them, at- } \\
\text { tendees collect from the booths }\end{array}$ & $\begin{array}{l}\text { Attendee clicks on icons to request good- } \\
\text { ies, and a Fulfillment Center handles the } \\
\text { deliveries to attendees }\end{array}$ \\
\hline $\begin{array}{l}\text { Product/ Service In- } \\
\text { formation }\end{array}$ & Exhibitors give away product brochures & $\begin{array}{l}\text { Online attendees click on an icon to down- } \\
\text { load a printable version of the catalog, or } \\
\text { request a fax or mailing of the catalog by } \\
\text { clicking on an icon }\end{array}$ \\
\hline Discussion & $\begin{array}{l}\text { Exhibitors engage attendees one-on-one } \\
\text { or in a group }\end{array}$ & $\begin{array}{l}\text { The exhibitors' online booth staffers handle } \\
\text { attendees one-on-one through chat lines, } \\
\text { instant phone calls, or video conferencing }\end{array}$ \\
\hline $\begin{array}{l}\text { Keynote Speeches / } \\
\text { Press Releases }\end{array}$ & $\begin{array}{l}\text { Exhibitors hold their press conferences or } \\
\text { demo sessions at the booth }\end{array}$ & $\begin{array}{l}\text { Exhibitors can have real time press releas- } \\
\text { es, press conferences, and chat interviews. } \\
\text { Keynote speeches streamed. Webinars } \\
\text { provide more in-depth learning experienc- } \\
\text { es. }\end{array}$ \\
\hline The Café & People meet informally over coffee. & $\begin{array}{l}\text { A Bulletin Board provides feedback and } \\
\text { "graffiti" for the event, and a common chat } \\
\text { room allows people to exchange views }\end{array}$ \\
\hline $\begin{array}{l}\text { Food Receptions, } \\
\text { Tourism }\end{array}$ & $\begin{array}{l}\text { Allows participants to have fun and net- } \\
\text { work; builds goodwill toward the compa- } \\
\text { nies providing the receptions }\end{array}$ & $\begin{array}{l}\text { Food and tourism not replicated but cou- } \\
\text { pons can be given away by the conference } \\
\text { organizer or by vendors }\end{array}$ \\
\hline $\begin{array}{c}\text { Simultaneous } \\
\text { one-on-one Conver- } \\
\text { sations (chat) }\end{array}$ & Impossible & $\begin{array}{l}\text { Possible to hold multiple chat sessions } \\
\text { simultaneously with different participants }\end{array}$ \\
\hline
\end{tabular}

The event producers and exhibitors also work with the technology platform. The virtual tradeshow organizer requests a virtual trade fair technology provider to create an instance of the virtual event for a specific event using customized messaging, images, cost parameters, etc. Event producers promote the virtual show in the same way as they would a physical show. Virtual trade fair booths are created online when exhibitors select booth specifications within those stipulated by the show's producers. Lead-generation reports delivered to exhibitors allow them to tune their booth offerings and display services as close to real time as possible. These reports also allow them to follow up with qualified leads immediately. The process as shown in Figure 3 includes content creation, show time, and reporting. 

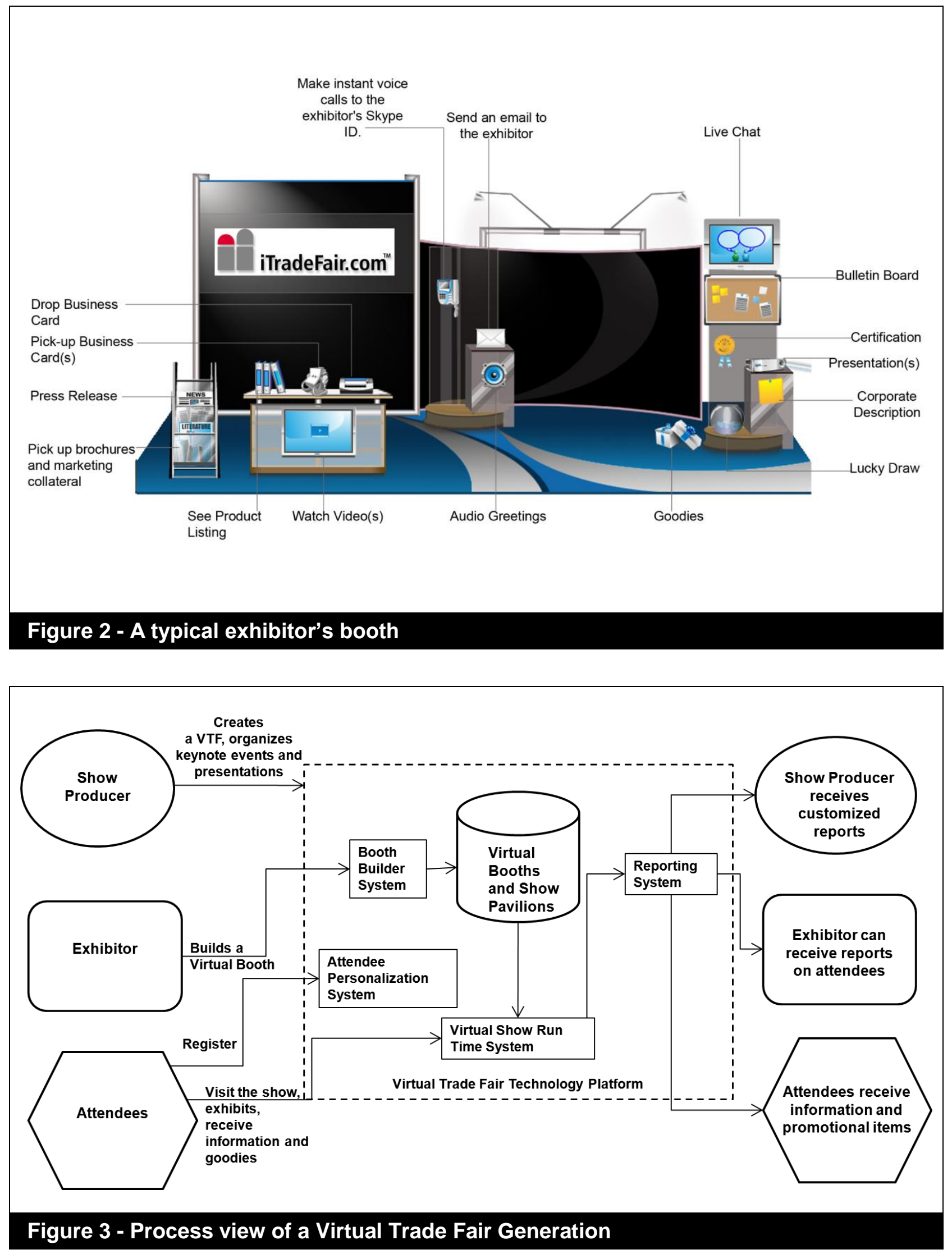
The development of our VTF platform was guided by Information Systems theories as shown in Table 2. In this table, we present 12 guidelines that are theoretically derived and the associated technology modules that we developed. The technology that makes all this possible is divided into four sections: the booth builder system, attendee personalization system, virtual show run-time system, and the online reporting system. These components are discussed in the next section..

\section{Table 2 - Theoretically driven design guidelines}

\begin{tabular}{|c|c|c|c|}
\hline Theory & \multicolumn{2}{|r|}{ Guideline } & \multirow{2}{*}{$\begin{array}{l}\quad \text { Suggested } \\
\quad \text { Trade Fair System Capabilities } \\
\text { Attendee personalization system: Registration, } \\
\text { visiting the show and exhibits, receiving infor- } \\
\text { mation and gifts etc. } \\
\text { Booth builder system: Organization of keynote } \\
\text { events and presentations etc. }\end{array}$} \\
\hline \multirow{8}{*}{$\begin{array}{l}\text { Task Technology Fit } \\
\text { (Goodhue et al. 1995) }\end{array}$} & [1] & $\begin{array}{l}\text { Task-technology fit: Create a } \\
\text { virtual tradeshow platform with } \\
\text { tasks that match those per- } \\
\text { formed in a physical tradeshow. }\end{array}$ & \\
\hline & [2] & $\begin{array}{l}\text { Quality: Create a virtual } \\
\text { tradeshow platform with quality } \\
\text { data, current data, right data, } \\
\text { and right level of detail. }\end{array}$ & $\begin{array}{l}\text { Booth builder system: Enable show producers } \\
\text { and exhibitors to update information as need- } \\
\text { ed } \\
\text { Reporting system: Enable exhibitors to re- } \\
\text { ceive information on booth activities by at- } \\
\text { tendees, literature requested report, business } \\
\text { cards etc. }\end{array}$ \\
\hline & [3] & $\begin{array}{l}\text { Locatability: Create a virtual } \\
\text { tradeshow platform with data } \\
\text { that is easy to locate and the } \\
\text { meaning of the terms clear. }\end{array}$ & $\begin{array}{l}\text { Booth builder system: Control of booth con- } \\
\text { tent in the hands of the exhibitor, this includes } \\
\text { signs, colors and any other branded items } \\
\text { specific to the industry and company. } \\
\text { Organize booths in pavilions for easy naviga- } \\
\text { tion }\end{array}$ \\
\hline & [4] & $\begin{array}{l}\text { Authorization: Create a virtual } \\
\text { tradeshow platform with appro- } \\
\text { priate levels of access }\end{array}$ & $\begin{array}{l}\text { Virtual show run-time system: Allow for differ- } \\
\text { ent levels of access: show producer, exhibitor, } \\
\text { exhibitor staff chat operators, attendees, } \\
\text { speakers, etc. }\end{array}$ \\
\hline & [5] & $\begin{array}{l}\text { Compatibility: Create a virtual } \\
\text { tradeshow platform with con- } \\
\text { sistent data fields }\end{array}$ & $\begin{array}{l}\text { Booth builder system: Store and organize VTF } \\
\text { information in databases. }\end{array}$ \\
\hline & [6] & $\begin{array}{l}\text { Production timelines: Create a } \\
\text { virtual tradeshow platform that } \\
\text { can be implemented in a timely } \\
\text { manner }\end{array}$ & $\begin{array}{l}\text { Booth builder system: Easy to use browser } \\
\text { based platform, library of both skins and } \\
\text { graphical images, self-contained application }\end{array}$ \\
\hline & [7] & $\begin{array}{l}\text { Systems reliability: Create a } \\
\text { virtual tradeshow platform that is } \\
\text { reliable }\end{array}$ & $\begin{array}{l}\text { Technology components: No special down- } \\
\text { loads beyond a desktop browser, commercial- } \\
\text { off the shelf software etc. }\end{array}$ \\
\hline & [8] & $\begin{array}{l}\text { Relationship with users: Create } \\
\text { a virtual tradeshow platform that } \\
\text { relates well with tradeshow or- } \\
\text { ganizers, exhibitors and at- } \\
\text { tendees }\end{array}$ & $\begin{array}{l}\text { Technical support: White papers on virtual } \\
\text { trade fairs, e-book on designing virtual job-fair, } \\
\text { availability of technical help }\end{array}$ \\
\hline
\end{tabular}


A Design Science Approach to Virtual World Implementation of Trade Fairs/Sharda et al.

\begin{tabular}{|c|c|c|c|}
\hline $\begin{array}{l}\text { Task Technology Fit } \\
\text { (Goodhue et al. 1995)/ } \\
\text { Technology } \\
\text { Acceptance Model } \\
\text { Davis 1989) }\end{array}$ & [9] & $\begin{array}{l}\text { Ease of use/training: Create a } \\
\text { virtual tradeshow platform that } \\
\text { is easy to use and easy to train } \\
\text { users }\end{array}$ & $\begin{array}{l}\text { Booth builder system: Knowledge of HTML or } \\
\text { any other programming language not required; } \\
\text { easy to use point-and-click functionality. } \\
\text { Attendee personalization system: Mimic the } \\
\text { experience of an attendee at a physical event, } \\
\text { easy control and manipulation of settings. }\end{array}$ \\
\hline $\begin{array}{l}\text { Media Richness } \\
\text { Theory } \\
\text { (Daft et al. 1986)/ } \\
\text { Collaborative } \\
\text { Systems } \\
\text { (DeSanctis 1987) }\end{array}$ & [10] & $\begin{array}{l}\text { Create a virtual tradeshow plat- } \\
\text { form that provides multiple } \\
\text { communication channels be- } \\
\text { tween participants }\end{array}$ & $\begin{array}{l}\text { multiple systems:: Web-call back, video- } \\
\text { conferencing, online chat, e-mail, memos, } \\
\text { letters, faxes, PowerPoint presentations etc. } \\
\text { Virtual show run-time system: Online discus- } \\
\text { sion boards, online live-chat forums allowing } \\
\text { many-to-many discussions and debates, } \\
\text { search-engine functionality etc. }\end{array}$ \\
\hline \multirow{2}{*}{$\begin{array}{c}\text { Collaborative } \\
\text { Systems } \\
\text { (DeSanctis 1987) }\end{array}$} & [11] & $\begin{array}{l}\text { Create a virtual tradeshow plat- } \\
\text { form with a common viewing } \\
\text { screen }\end{array}$ & $\begin{array}{l}\text { Virtual show run-time system: Webinars and } \\
\text { booths can be visited by many simultaneously }\end{array}$ \\
\hline & [12] & $\begin{array}{l}\text { Create a virtual tradeshow plat- } \\
\text { form with a time clock and auto- } \\
\text { matic display of agenda items }\end{array}$ & $\begin{array}{l}\text { Allow for common information display on the } \\
\text { show homepage }\end{array}$ \\
\hline
\end{tabular}

\section{Implementation of the Artifact}

In this section we describe the implementation of the artifact consisting of four technology components: the booth builder system, attendee personalization system, virtual show run-time system, and the online reporting system.

\section{Booth Builder System}

In traditional tradeshows, booth design is focused on , communication(Kirchgeorg. et al., 2005). In such tradeshows, good booth design focuses on the product and ways to increase the number of visitors or attendees coming to the booth. Most organizations hire experts to design their booths, which adds to the expense (Miller 1999). In contrast, our VTF platforms can provide exhibitors with tools to develop professional-looking virtual booths. The booth builder software puts control of the booth's contents in the exhibitors' hands; they can easily customize everything to their satisfaction. Through a browserbased interface, the exhibitor can create and edit any of the booth's contents, even when the event is in progress. In a physical event, this would be very disruptive and expensive. Generally, no knowledge of HTML or any other programming language is required and exhibitors can make the changes they want without consulting the tradeshow producer. Using "Booth Skins", the exhibitor picks from a library of graphical images. Because color has been shown to be one of the biggest influences on the human psyche (Siskind, 2005), our booth builder system allows exhibitors to pick colors that match their corporate colors and culture. In addition, vendors can add signs and graphics that match their brand. Sound can be added to enhance the visitors' experience. This is also the place where all other relevant information is entered, for example, specific literature, videos, presentations, giveaways at the booth, phone numbers that are connected when an attendee requests a call, etc. Booth builder is a completely self-contained application with built-in features that simplify complex functions into easy-to-use, point-and-click actions enabling the virtual exhibit to be easily built.

\section{Attendee Personalization System}

Thousands of attendees can visit a virtual tradeshow, possibly visiting hundreds of booths each. Attendees register through a simple set of forms, different for each virtual show. The virtual show producer sets the 
access policy for the event and allows participation after certain registration conditions have been met. This process gives the producer the opportunity to ensure that appropriate, qualified attendees participate. In the same way that a trade magazine collects additional demographics for free subscriptions, the registration may prompt attendees for additional information, which the producer may choose to make mandatory or voluntary. The registration system sends an email to each attendee after he or she registers, asking him or her to click on a validation link. This step, allows the system to check whether the email address used by the attendee is valid. The VTF platform allows attendees to customize their own visit at a virtual event. Using the MyStuff features, attendees control a series of settings that can enhance and optimize the time they spend at the virtual show. They can take advantage of personalized services such as creating their own itinerary to guide them through the show floor or by creating, printing, and emailing a notepad with notes made during visits to specific booths. These features mimic the experience of an attendee at a physical event.

\section{Virtual Show Run-Time System}

A trade fair participant goes to a specific VTF homepage and logs in with information about a specific show. The participant first visits a virtual exhibit floor. On the virtual exhibit floor, the participant can pick from virtual booths offering rich interactive tools for live interaction and information dissemination. A visual representation of the VTF allows viewers to stroll around the booths using their computer mouse. Technologies enable communication through features such as chat, web callback, FAX server, and email. Direct two way video chats can also be enabled. Participants have access to community-building features such as online discussion boards and online livechat forums that allow many-to-many collaboration for discussion and debate, followed by online surveys, and a search-engine for searches based on keyword and state. Participants can experience a virtual pressroom with press releases from various virtual booths, virtual media kits, and a virtual chat forum for meeting with members of the media. Special speakers or guests can communicate through video-streamed keynote web-casts. Thus VTF replicates the experience of a physical event to a large extent. All these features are served by the show run-time system.

\section{Online Reporting System}

One of the main reasons for exhibitors to participate in trade fairs is to acquire new leads and contacts. The exhibitor typically wishes to collect the following types of information (Miller, 1999; Siskind, 2005):

i Complete identification of the prospect including name, company, address, phone, fax number, and email address.

ii Specific product interest and area of use

iii Budget and buying time frame

iv Other buying interests, for example who else is involved in the buying process or who makes the final buying decision.

v Comments, objections, concerns and anything else attendees would like to communicate.

vi Name of tradeshow and date held

vii Information on post-show follow up; whether they need a phone call or extra literature?

viii Personal comment on prospect, something a booth staffer can use to personalize the meeting notes.

In a virtual show all exhibitors can receive attendee leads in real time. A generic attendee report (similar to traditional show attendee lists) containing every registered attendee is available to all exhibitors through the event producer. Exhibitors can also access detailed traffic reports of all attendees that visit their virtual booth. The report includes all attendees' names, titles, and relevant contact information and whether the attendee has requested additional information on any products and services, the company in general, or employment opportunities. A "Literature Requested Report" lists the attendees who requested that literature be mailed to them. Similarly a "Goodies Re- 
quest Report" can be generated. A comprehensive "Booth Footprints Report" is available on all registered attendees that view an exhibitor's virtual booth. This report provides insight into what is of interest to each specific visitor. In addition, attendees visiting the booth can drop a business card; a report of the cards left is also available. For obvious privacy and security purposes, all reports are under controlled access.

\section{Technology Components}

This virtual event platform was built using commercial off-the-shelf software. At the core of the system is a database management system that manages all the information from the show producers, exhibitors, and attendees. The database contains numerous tables related to participating entities, each of the features, and all the reports generated through event participation. All show-relevant information is stored in customized XML files so that presentation functionality is independent of the database content. All of the system components were written in VB and ASP.NET as specific functionality components. These core components form the intellectual property of the technology provider, iTradeFair.com.

\section{Evaluation of the Artifact}

In this section we evaluate the artifact that we have developed. We describe applications of the technology platform, an observation of the effectiveness and efficiency of a specific virtual event implementation, a survey evaluation of the virtual event participation and finally mention the iterative process from evaluation back to design.

\section{Applications of the Technology Plat- form}

The technology framework described in this paper has been utilized to host over 60 virtual events as of June 2012 by a variety of organizers. These events occurred in different industries; the types of events and durations varied. Some events were held as supplements to traditional $\mathrm{B} 2 \mathrm{~B}$ tradeshows; others were purely virtual events. For example, the Fire Engineering Virtual Trade Show featuring over 650 exhibitors extended the in-person tradeshow of a large publishing company. The entire event was created within a week, with each exhibitor populating his or her own booth independently with rich media. Other shows in this genre include trade fairs for the promotional products industry, geriatric care, oil industry, educational communication technology industry, industrial products, the fabless semiconductor industry, and a congress of surgeons,. A second category of shows promoted interaction between entrepreneurs and venture capitalists, for example, when a global conglomerate in the healthcare industry wanted to let startup technology firms interact with decision-makers in various divisions worldwide. Some virtual fairs were held as a bridge across distances and time-zones. A trade show held for the Dubai Electricity and Water Authority not only extended the duration of its in-person trade show by putting it online, but also extended the visibility for the exhibitors to visitors from all of the Middle East and Europe. A similar show was a trans-Atlantic trade show that was held entirely online with no f2f counterpart, featuring companies based in the U.K. seeking to find buyers and business partners in the USA.

The matchmaking capability that was finetuned for these specialized corporate applications of virtual fairs has been used in yet other areas. For example, our technology platform has also been used in bringing prospective college students together with a university's departments to reduce required travel on the part of students who want to learn more about a prospective school.

\section{A Specific Virtual Event Implementa- tion}

Virtual career fairs are a natural progression from other types of virtual fairs or tradeshows. The University of Maryland University College (UMUC) has organized such virtual career fairs for several years now. UMUC added a virtual job fair to its career services program (including on-campus career fairs) to expand the reach of employers to a wider audience of potential job candidates. As a globallyfocused university serving more than 90,000 
students worldwide, UMUC courses and programs are presently available at over 70 sites throughout Europe and the Middle East and about 50 sites throughout Asia and the Pacific. Currently, UMUC enrolls close to 60,000 active duty military, reserves, dependents and veterans through their online and remote site degree programs. The virtual career fair connects the distance learning graduates to companies they might not otherwise have the opportunity to meet.

UMUC worked with iTradeFair.com to use the technology platform described in this paper to host this virtual event. The Career Services office of UMUC invited potential recruiters at UMUC to participate in the virtual career fair. These would-be employers used the booth builder system within the technology platform to build their virtual booths. Students at UMUC were invited to register and participate in the virtual event. Participating students registered through the attendee personalization system. On the days of the virtual career fair, attendees and exhibitors used the show run-time system to interact with each other and exchange information. Job seekers gathered information on available jobs, while the employers collected resumes and also conducted preliminary interviews through the virtual career fair system. The exhibitors also were able to download any relevant reports though the reporting system.

The following analysis is based on data collected from one virtual career fairs held in February 2008. There were 686 attendees from 250 different cities including 192 outside the state of Maryland and 14 from outside the U.S. from as far away as Guam, Korea, and Siberia. One attendee was even from a naval warship in the middle of the Pacific Ocean. There were 32 exhibitors across a wide range of businesses including banking, medical, IT, and retail.

\section{An Evaluation of Virtual Event Partici- pation}

We conducted a survey of the virtual career fair attendees and exhibitors to understand the value of such technologies in a real business setting. Survey questions were gener- ated using tradeshow and Information Systems literature. The three broad focus areas for assessment were event effectiveness, system effectiveness, and event efficiency. To measure system effectiveness and event efficiency, we produced questions using the categorical success measures developed by Saarinen (Saarinen, 1996). Saarinen identified four main dimensions of IS success: (1) the development process, (2) the use process, (3) quality, and (4) impact. Ten items were selected from these four dimensions, two each from development and impact and three each from use process and quality. The items from the impact dimension were used to measure event efficiency. These items measure the value derived from an event relative to the resources invested. To generate event effectiveness items, we initially reviewed an expanded instrument for evaluating information systems success developed by DeLone (DeLone et al., 2003). This review led to our adoption of Hansen's performance scale to measure event effectiveness (Hansen, 2004). Hansen identified five performance measures for tradeshows: (1) sales-related, (2) information gathering, (3) relationship building, (4) image building, and (5) motivation. Because some of the relationship and image-building items did not apply to career fairs, those items were removed and the two measures combined. Thus a total of 18 questions were included in this survey, 8 on event effectiveness, 8 on system effectiveness, and 2 on event efficiency. Table 3 contains a complete list of the questions as well as descriptive statistics. The mean, standard deviation and mode from the responses for each question are reported.

To obtain the data for our study we asked both exhibitors and attendees to assess their experiences by responding to a structured survey. These questions employed a 5 point Likert scale to measure the direction and intensity of attitudes along an evenly spaced continuum. All questions were ordinal and assigned numerical codes from $1=$ strongly agree to 5 = strongly disagree. Survey participants were given the option of adding any comments they wished. 


\begin{tabular}{|c|l|c|}
\hline \multicolumn{2}{|l|}{ Table 3 - University of Maryland University College Virtual Career Fair 2008 Survey } \\
\hline & \multicolumn{1}{|l|}{ (Mean, S.D, Mode) } \\
\hline & Event effectiveness & $(3.02,1.06,4)$ \\
\hline 1. & I downloaded booth literature from every booth I visited. & $(2.72,1.05,2)$ \\
\hline 2. & I found the information I was looking for. & $(3.66,0.96,4)$ \\
\hline 3. & I developed meaningful relationships with exhibitors. & $(2.68,1.11,2)$ \\
\hline 4. & $\begin{array}{l}\text { The modes of communication were adequate to establish meaningful relationships. } \\
\text { (E.g. email, bulletin boards, drop box, chat, etc.) }\end{array}$ & $(2.59,1.14,2)$ \\
\hline 5. & I got a good feel for the exhibitor's organization. & $(2.76,1.20,2)$ \\
\hline 6. & I was able to adequately represent myself. & $(2.80,1.23,2)$ \\
\hline 7. & The experience was a motivator. & $(2.29,1.19,2)$ \\
\hline 8. & I will participate in another virtual job fair. & $(2.10,0.94,2)$ \\
\hline & System effectiveness & $(4.00,0.92,4)$ \\
\hline 9. & The user interface was easy to use. & $(2.73,1.12,2)$ \\
\hline 10. & I had technical issues using the interface. & $(4.20,0.81,4)$ \\
\hline 11. & The system facilitated communication with exhibitors well. & $(2.20,0.93,2)$ \\
\hline 12. & I required a lot of training to use the system. & $(2.73,1.16,3)$ \\
\hline 13. & The system made it easy to navigate around the job fair. & $(2.37,0.86,2)$ \\
\hline 14. & Compared to a traditional job fair the virtual job fair is quite effective. & $(2.12,0.87,2)$ \\
\hline 15. & I was very satisfied with the system response time. & $(2.20,1.12,1)$ \\
\hline 16. & The interface was user friendly. & $(1.68,0.85,1)$ \\
\hline & Event efficiency & \\
\hline 17. & The virtual job fair saved me time compared to traditional job fairs. & \\
\hline 18. & The job fair was within my budget. & \\
\hline
\end{tabular}

Because the survey subjects were either business professionals or recent graduates with an undergraduate degree or higher, the validity of our instrument rests soundly on the assumption that these observers will make good subjects for quantitative observations (Guilford, 1954). The questionnaire was emailed in Aug 2008 to the 686 virtual career fair attendees and a similar survey was sent to the 38 exhibitors. Forty-one attendee surveys were completed for a response rate of $7 \%$. Five exhibitor surveys were completed for a response rate of $15 \%$. The low response rate for this preliminary study is believed to be due in part to the transient nature of the attendee population and to the time lag between the event, which was held in February 2008, and the survey, which was administered in August 2008. Because of the low number of exhibitor responses, we do not report an in-depth statistical analysis of the sur- vey, instead we report some descriptive statistics for each question on the survey.

Our basic analysis of this preliminary dataset and the open-ended comments of the participants suggest that both exhibitors and attendees found the virtual career fair more efficient than traditional career fairs. As seen in Table 3 and the box-plot figure in Appendix A, the attendees rated the user interface as easy to use and that the virtual trade fair saved them money. This result was as expected due to the significantly lower cost of and increased accessibility to virtual events. As noted before, many students at UMUC are located at faraway places and thus would not be able to attend an f2f career fair. However, it appears that the attendees were not fully satisfied with the outcomes of the participation experience. The survey results indicate technical issues with the system expressed in a need for training as attendees adjusted to 
this new technology. This may mean that the system technology artifact is fine as far as it goes, but virtual event attendees are yearning for more intuitive platforms. Of course, such platforms will become more prevalent as we address the issues of technology, bandwidths, security, and privacy. Analysis of a larger sample size would also provide more descriptive insights.

The open-ended comments were informative as well. Several participants acknowledged the value of f2f meetings, but some participants noted the limited scope. "This virtual fair will not replace people in face to face interaction. This was more of an advertising vehicle for the companies that participated than an actual job fair." Others pointed out flaws in the virtual event: "A completely useless event because the [host-UMUC] failed to line up adequate employers compared to traditional job fairs in the same area." One comment introduced a concept we had not previously considered: "I would have liked to have been able to chat with multiple agencies at one time. ..." Meeting with multiple exhibitors at the same time is impossible at a traditional tradeshow or career fair, but the generation of new college graduates is accustomed to multitasking communication tools. One comment describes the true value of virtual career fairs and their place in the market: "There is no way that a virtual job fair can replace the opportunity to speak to a prospective employer face to face. However, if you start with the virtual job fair and follow this with face to face interviews . . . this is better than a traditional job fair."

To directly address the issue of event efficiency from the exhibitor perspective, we can estimate the CPL, in this context the cost per potential new employee. A booth at this virtual event cost $\$ 150$ (subsidized) and there was no cost to attend. Therefore, if a company called one or more of the attendees for a second interview, which is equivalent to a sales person calling on a potential new contact, the CPL was no greater than $\$ 150$. Another measure of success for a career fair is how well it matches people to jobs. The low response rate made it difficult to determine the actual number of attendees eventually hired by exhibitors. However, exhibitors reported that the virtual career fair was an excellent venue for the first screening of job applicants.

UMUC found the virtual career fair such a success that they have continued to host such virtual career fairs each year, the most recent being in April 2012. The UMUC Career Services is applying a combination of traditional and virtual career fairs to give their on-site students the opportunity to benefit from face-to-face interviews as well as connect their distance learning graduates to companies they might not otherwise have the opportunity to meet.

Although these results are based on a very preliminary analysis of a small sample of participants in a specific virtual event, we consider them promising. First, we can at least attempt to measure effectiveness and efficiency of participation in virtual events. Second, these early results demonstrate that the event efficiency may be the driver for now as we enhance technology to improve event and system effectiveness.

\section{Iterative Development}

The technology platform described in this paper is flexible and usable for many different types of events. With each event, specific functionality was added or customized to meet the needs of the events. For example, in one of the early virtual shows, the developers observed that the attendees did not connect with the booth hosts through the live chat system. Discussions indicated that the attendees did not see the option clearly. To replicate the "May I help you?" greeting of a physical booth visit, a short JavaScript code was added to open a popup window at a booth inviting the attendee to chat with a booth host. This simple option allowed the virtual booth hosts and attendees to connect with each other easily. However, many attendees found this popup to be intrusive, so the feature was eventually dropped.

Another example of iterative development of the artifact is an itinerary scheduler. In virtual 
events as well as physical events, it is common for attendees and exhibitors to schedule a time to get together. In a virtual event, such scheduling may be even more important because the participants are usually at their workplace and have to juggle between their local work schedule and virtual event participation. Thus an itinerary scheduler was developed to allow attendees and exhibitors to create a schedule for interviews, discussions, etc. This option has been especially popular in supplier diversity shows where the purchasing managers from large organizations (attendees) wanted to learn more about specific minority suppliers (exhibitors).

A related example of iterative development of specific features is a display of Minority and Women Business Enterprises (MWBE) certification. Purchasing managers in supplier diversity fairs wanted to make sure that the exhibitors were truly certified as minority/women-owned businesses. Such certification is commonly displayed in a physical event, and the purchasing managers wished to see it when they visited a virtual booth. A certification display feature was added to the system so that the exhibitors could upload a scanned image of the certificate, which the attendee could quickly see in the virtual booth. Our experience demonstrates that a good design-science artifact needs to go through interactive processes.

\section{Implications and Conclusion}

This specific application of virtual worlds and a preliminary evaluation of one specific event provides interesting potential for practitioners and future opportunities for IS researchers. Virtual worlds in general have to be viewed as one more technology to pursue in online marketing (Albert et al., 2004). Platforms such as the one reported here can enable same-time, different-place gatherings for many exhibitors and attendees. Complementary virtual events have the potential to expand the reach of a booth in a trade fair to attendees who could not attend an event physically but may attend it virtually, and thus lower the cost per lead. This concept is still in an early stage, but offers significant poten- tial. Virtual world platforms such as Second Life enable a company to have a permanent presence in the virtual world, but the challenge of attracting visitors to the permanent virtual world presence (Island) remains. Also to overcome is the restriction on installation of specialized applications on corporate desktops.

Industry-specific gatherings made possible through virtual event platforms need to be further explored for their capability and effectiveness. For example, in industries where technology is changing rapidly, it may be possible to organize a physical trade show annually, yet organize virtual complements on a quarterly or even monthly basis so that industry participants can learn about the latest developments quickly. There are, of course, challenges to adoption of virtual world technologies in general and virtual event technologies in particular. For example, most people like to travel to a conference location for fun as well as work. Will these individuals just attend the event virtually? Certainly not! Our conjecture is that virtual events work well in cases where the constraints of travel (time, money, legal restrictions) do not permit travel to a meeting. Extending an event's reach to this audience can be a win-win for both the event attendees and exhibitors, and therefore, event organizers. From the marketing manager's standpoint, a virtual event offers one more channel whose ROI must be estimated and evaluated before investing scarce marketing dollars. Determining appropriate applications of virtual events can help us leverage the research on task-technology fit (Goodhue et al., 1995) to determine where such virtual world applications are likely to succeed.

Another challenge that we have observed through our participation in virtual events is ensuring that the attendees are able to participate in the event. With a physical event, attendees travel away from their work location and thus are not distracted by their office work (though other interruptions such as email, phone, and tourism remain potential distractions). With a virtual event, an attendee has to plan to attend the event and not be 
distracted by other things happening in the office. Distractions can be reduced somewhat by attendees' blocking time on their calendars for participation in the virtual events and then receiving timely reminders, but distractions are still a challenge.

The results presented in this paper also reveal interesting opportunities for IS researchers and technology developers. The preliminary results of a survey of exhibitors and attendees in one specific type of virtual event show that the efficiency of event participation is easy to see, but the effectiveness is mixed. A key challenge for technology developers and design science researchers relates to increasing the effectiveness of virtual events of this type. Should there be more and better graphics? Is a greater immersive view possible? Should there be even richer communication within an event? How can we enable chance meetings among attendees? Virtual events can facilitate other types of conversations; for example; translation technologies may be useful in enabling chat conversations between participants who speak different languages. An attendee could type a question in Spanish, the exhibitor could receive and answer the question in English, and the attendee would receive the answer back in Spanish. Although translation services are far from perfect, they may be satisfactory for initial introduction and lead collection purposes. Evaluations of such innovative technologies in virtual worlds present interesting research opportunities.

Of course, any additional technology infusions must also be balanced against privacy and security issues and organizational restrictions on installations of plug-in applications. Achieving this optimal balance between technology and security/privacy considerations is an open area for further research. Virtual world technologies are likely to push the technology edge for organizations and thus will result in recurrence of this question for a long time. What type and extent of interruptions will the attendees tolerate in the virtual world? If someone is logged into a vir- tual event and starts to work on other knowledge work (email or any other knowledge work), is a booth host permitted to proactively engage the attendee by presenting a "May I help you?" type message to the attendee?

Introduction of new technology capabilities also poses research opportunities for human computer interaction $(\mathrm{HCl})$ researchers. For example, at a physical event, it is usually obvious to the attendee as to what to do at that booth and how. As we attempt to make the virtual event resemble the physical event, the two-dimensional screen and the limited screen space present the challenge of how to make it intuitively obvious what a booth visitor can do there and how. Optimal placement of all the activity options within a virtual booth to enable satisfactory interaction between an exhibitor and the attendees is an open question at this point. Perhaps some research from the technology acceptance model perspective (Davis, 1989) can help us answer such questions. Will simplicity (e.g. Google) be better than an immersive feel (e.g. Second Life)? Or is there a middle ground, and if so, how do we determine it? Researchers interested in computer supported collaborative work finally have the bandwidth and mechanisms in place to study the potential of rich media and learn how the interactions can be improved.

\section{Acknowledgements}

We thank Dr Lisa Andrews, Director, Career Services at University of Maryland University College for giving us permission to contact the participants in the UMUC Virtual Career Fair 2008. We also acknowledge Frances Griffin for her editorial inputs on early drafts of this paper. Finally, we recognize Sanjay Venkataswarulu, Vishal Jangla, George Gavula, Lissa Guillett, and several other programmers for their work in implementing the technology platform. 


\section{References}

Albert, T.C., Goes, P.B., and Gupta, A. (2004). "GIST: A Model For Design and Management of Content and Interactivity of Customer-Centric Web Sites," MIS Quarterly, 28(2) pp. 161181.

Armstrong, L. (2003). "Ballpark Budgeting," Retrieved from http://www.exhibitoronline.com/exhibit ormagazine/article.asp?ID $=449$ on June 14, 2012.

Ashley, J. (2003). "Synchronous and Asynchronous Communication Tools," Retrieved from http://www.asaecenter. org/PublicationsResources/articledeta il.cfm?ItemNumber $=13572$ on June 14, 2012.

Chaturvedi, A. R., Dolk, D. R., \& Drnevich, P. L. (2011). "Design Principles for Virtual Worlds", MIS Quarterly, 35(3), pp.673-684.

Clemmer, G. (2008). "Self-Storage Research Semiannual Report," Retrieved from http://www.marcusmillichap.com/servi ces/research/reports/National/Marcus Millichap NationalSelfStorageReport. pdf on June 14, 2012.

Cronbach, L.J. (1951). "Coefficient alpha and the Internal Structure of Tests," Psychometrika (16), pp. 297-334.

Daft, R.L., and Lengel, R.H. (1986). "Organizational Information Requirements, Media Richness and Structural Design," Management Science 32(5) pp.554-571.

David, A.B., and Benn, R.K. (2007)."Virtual Worlds: Multi-disciplinary Research Opportunities," SIGMIS Database 38(4) pp. 17-25.

Davis, F.D. (1989). "Perceived Usefulness, Perceived Ease of Use, and User Acceptance of Information Technology," MIS Quarterly 13(3), pp. 319-340.

DemandGen. (2008). "B2B Marketers Pushing to Improve Campaign Cost Per
Lead Metrics," Retrieved from http://www.demandgenreport.com/arc hive.php?codearti=1083 ) on June 14, 2012.

DeSanctis, G. and Gallupe, R . B ., (1987). "A Foundation for the Study of Group Decision Support Systems," Management Science (33), pp. 589-609.

DeLone, W.H., and McLean, E.R. (2003)."The DeLone and McLean Model of Information Systems Success: A Ten-Year Update," Journal of Management Information Systems 19(4), pp. 9-30.

Ducate, L.D. (2004). "The U.S. Exhibition Industry - Yesterday, Today and Tomorrow," Retrieved from http://www.ceir.org on June 14, 2012.

E\&E. (2008). "How Do I Select the Right Trade Booths and Shows for My Company?" Retrieved from http://www.exhibitsusa.com/PagEdindex-topic id-0-page id-279.phtml on June 14, 2012.

Evans, K.S. (2008). "Guidance on the Federal Desktop Core Configuration (FDCC)" Retrieved from http://www.whitehouse.gov/omb/mem oranda/fy2008/m08-22.pdf on June 14, 2012.

Gaffney, A. (2008). "B2B Marketers Pushing to Improve Campaign Cost Per Lead Metrics," Retrieved from http://www.demandgenreport.com/arc hive.php?codearti=1083) on June 14, 2012.

Good, R. (2005). "What is Web Conferencing?" Retrieved from http://www.masternewmedia.org/repor ts/webconferencing/guide/what_is_we b_conferencing.htm on June 14, 2012.

Goodhue, D.L., and Thompson, R.L. (1995). "Task-Technology Fit and Individual Performance," MIS Quarterly 9(2), pp. 213-236. 
Gopalakrishna, S., and Lilien, G.L. (1995a). "A Three-stage Model of Industrial Trade Show Performance," Marketing Science 14(1), pp. 22-42.

Gopalakrishna, S., Lilien, G.L., D, J., and Sequeira, I.K. (1995b). "Do Trade Shows Pay off,?" Journal of Marketing 59(3), pp. $75-84$.

Guilford, J.P. (1954). Psychometric Methods, (2 ed.) New York, McGraw-Hill.

Hansen, K. (2004). "Measuring performance at Trade Shows: Scale Development and Validation," Journal of Business Research (57:1), pp. 1-13.

Hevner, A.R., March, S.T., Park, J., and Ram, S. (2004). "Design Science in Information Systems Research," MIS Quarterly 28(1), pp. 75-105.

Iris, A.J., and Douglas, J.S. (2007). "The Virtual Sandbox," SIGMIS Database 38(4), pp 26-28.

Kare, H. (1996)."The Dual Motives of Participants at International Trade Shows: An Empirical Investigation of Exhibitors and Visitors With Selling Motives," International Marketing Review 13(2), pp. 39-53

Kerin, R.A., and Cron, W.L. (1987)."Assessing Trade Show Functions and Perfomance: An Exploratory Study," Journal of Marketing (61), pp. 87-94.

Kil-Soo, S., Hongki, K., \& Eung Kyo, S. (2011). "What if your Avator Looks Like You? Dual-Congruity Perspectives for Avatar Use," MIS Quarterly, 35(3), pp.711-A4.

Kirchgeorg., M., Dornscheidt., W.M., Giese., W., and Stoeck, N. (eds.) (2005). Trade Show Management: Planning, Implementing and controlling of Trade Shows, Conventions and Events. Leipzig, Germany, Gabler,.

Lakshmi, G., and Elham, M. (2007). "vCRM: Virtual Customer Relationship Man- agement," SIGMIS Database 38(4), pp. 56-60.

Lee-Kelly L., David, G., and Nada, F.A.-S. (2004). "Virtual Exhibitions: An Exploratory Study of Middle East Exhibitors' Dispositions," International Marketing Review 21(6), pp. 634-643

March, S.T., and Smith, G.F. (1995). "Design and Natural Science Research on Information Technology," Decision Support Systems 15(4), pp. 251-266.

Markoff J. (2004)." Technology; Comdex, the Computer Show, Canceled for Lack of Interest ". Retrieved from http://query.nytimes.com/gst/fullpage. $\mathrm{html}$ ?res=9E00E0DE1E39F937A1575 5C0A9629C8B63 ). on June 15, 2012.

Mikko J., Samuli P. (2007). From Technology Engineering to Social Engineering: 15 Years of Research on Virtual Worlds. Database for Advances in Information Systems, 38(4), 11-16.

Miller, S. (1999). How to Get the Most out of Tradeshows, (3 ed.) Chicago, II., NTC/ Contemporary Publishing Group.

Nah, F., Eschenbrenner, B., \& DeWester, D. (2011). "Enhancing Brand Equity Through Flow and Telepresence: A Comparison of 2D and 3D Virtual Worlds," MIS Quarterly, 35(3), pp.731A19.

Nunamaker Jr, J.F., Chen, M., and Purdin, T.D.M. (1990). "Systems Development in Information Systems Research," Journal of Management Information Systems 7(3), pp. 89-106.

Peffers, K.E.N., Tuunanen, T., Rothenberger, M.A., and Chatterjee, S. (2007). "A Design Science Research Methodology for Information Systems Research," Journal of Management Information Systems, 24(3), Winter2007/2008, pp. 45-77.

Saarinen, T. (1996). "An Expanded Instrument for Evaluating Information Sys- 
tem Success," Information and Management 31(2), pp. 103-118.

Sandler, G. (1994)."Fair Dealing, " The Journal of European Business, 5(4), pp. 46-52.

Siskind, B. 2005. Powerful Exhibit Marketing, The Complete Guide to Successful Tradeshows, Conferences and Consumer Shows, New York, Wiley.

Stuart, B. (2007)."Virtual worlds as a Medium for Advertising," SIGMIS Database 38(4), pp. 45-55.

\section{About Authors}

Ramesh Sharda is Director of the Institute for Research in Information Systems (IRIS), ConocoPhillips Chair of Management of Technology, and a Regents Professor of Management Science and Information Systems in the Spears School of Business at Oklahoma State University. His research has been published in major journals in management science and information systems, including Management Science, Information Systems Research, Decision Support Systems, Interfaces, INFORMS Journal on Computing, Computers and Operations Research, and many others. He serves on the editorial boards of journals such as the INFORMS Journal on Computing, Decision Support Systems, ACM Transactions on Management Information Systems, and Information Systems Frontiers. His research interests are in decision support systems, especially neural network applications, and technologies for managing information overload. His team's work on forecasting box office revenue of movies has received a lot of press. The Defense Ammunitions Center, National Science Foundation (NSF), US Department of Education, Marketing Science Institute, and other organizations have funded his research. $\mathrm{He}$ is also a cofounder of a company that produces virtual trade fairs, iTradeFair.com.

David Sikolia is a PhD student in the Department of Management Science and Information Systems in the Spears School of
Tradeshow. (2012). Merriam-Webster online, Retrieved from http://www.merriamwebster.com/dictionary/tradeshow on June 14, 2012.

Tsz-Wai, L., Gabriele, P., and Blake, I. (2007). "Marketing Strategies in Virtual worlds," SIGMIS Database 38(4), pp 77-80.

Wasko, M., Teigland, R., Leidner, D., \& Jarvenpaa, S. (2011). "Stepping into the Internet: New Ventures in Virtual Worlds," MIS Quarterly, 35(3), pp. 645-652.

Business at Oklahoma State University. He holds a B.Sc. Computer Science from Africa Nazarene University and a Masters in Information Systems from Baylor University. His research interest lies in information security policy compliance, application of the RFID technology in agriculture, Virtual worlds and Knowledge sharing. His work has been published in the Midwest Association for Information Systems (MWAIS) and the Cutter IT Journal.

Lt Col Joseph Thomas is an Assistant Professor in the Department of Management at the United States Air force Academy (USAFA) and also a PhD. Candidate in the Department of Management Science and Information Systems in the Spears School of Business at Oklahoma State University.

Ramesh Sambasivan, is the co-founder of iTradeFair.com, Inc., a technology company that uses its software platform to deliver specialized virtual events and promotional tools, served on a Software-as-a-Service model. Prior to co-founding iTradeFair.com, Ramesh was a management consultant with PricewaterhouseCoopers delivering technology and business transformation projects for large corporations, and a Business Analyst at American Airlines. Ramesh has an MBA from Oklahoma State University, and is a certified cost accountant from the Institute of Cost and Works Accountants of India. 
Pacific Asia Journal of the Association for Information Systems, Vol. 4, Iss. 2 [2012], Art. 4

Privacy and Security Aspects of Social Media: Institutional and Technological Environment / Kshetri

\section{Appendix A}

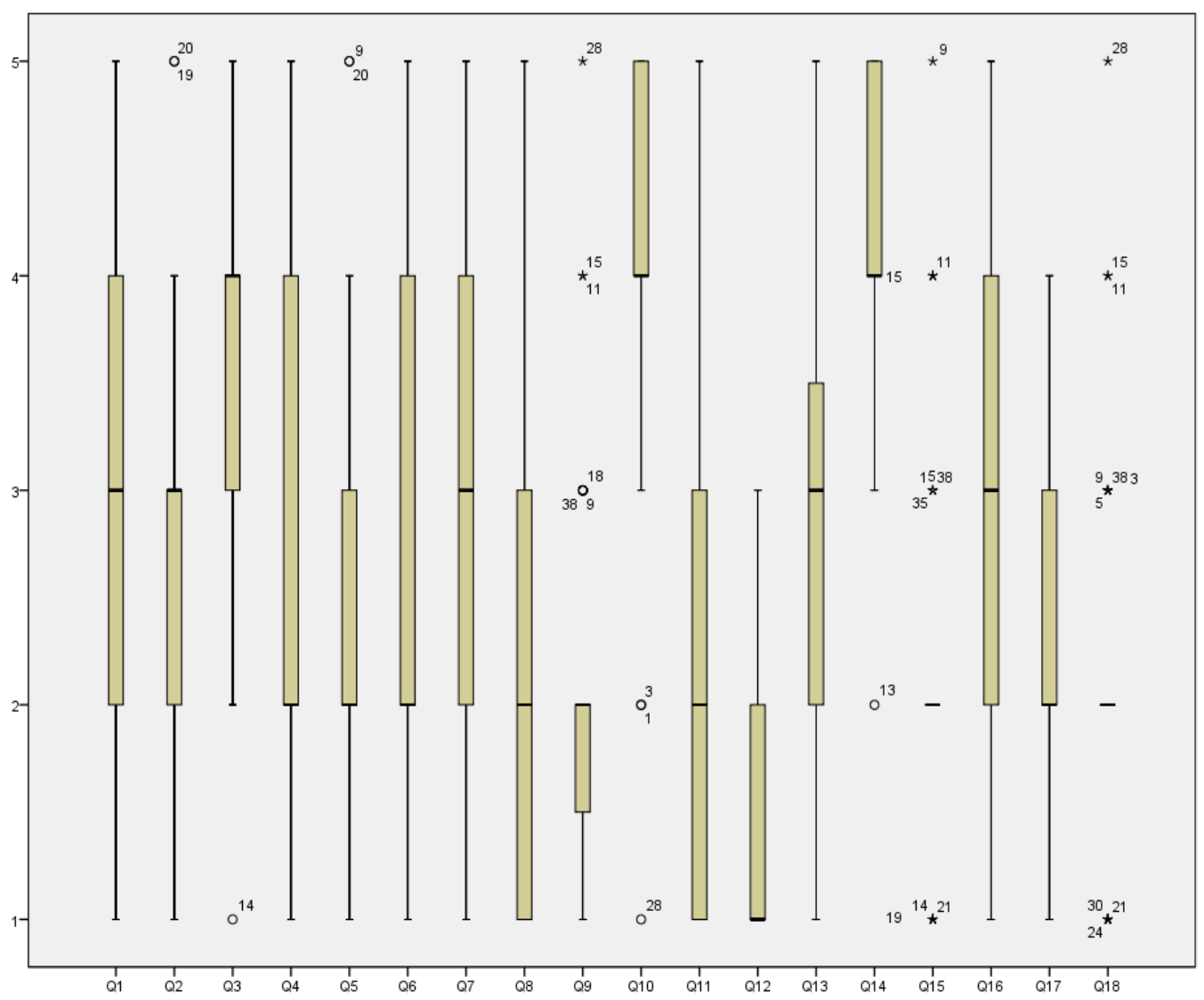

Q1 corresponds with question 1 in Table 3 and is the same for all the questions to Q18.

Figure 1 - University of Maryland University College Virtual Career Fair 2008 Survey questions box-plot chart 